\title{
Synthesis of calcium carbonate particles with carboxylic-terminated hyperbranched poly(amidoamine) and their surface modification
}

\author{
Yuka Tanaka and Kensuke Naka \\ Size-controlled $\mathrm{CaCO}_{3}$ particles were obtained using a carbonate-controlled addition method with a carboxylate-terminated \\ hyperbranched poly(amidoamine) (HYPAM-ONa). The crystalline phase of $\mathrm{CaCO}_{3}$ particles was determined to be \\ thermodynamically unstable vaterite. The average size of the $\mathrm{CaCO}_{3}$ particles decreased from $1.3 \pm 0.2$ to $0.36 \pm 0.18 \mu \mathrm{m}$ \\ with an increase in the incubation time of HYPAM-ONa-Ca ${ }^{2+}$ solution from $3 \mathrm{~min}$ to $72 \mathrm{~h}$. Interactions of the $\mathrm{CaCO}_{3}$ particles \\ in aqueous dispersions with different types of commercially available ionic polymers that is, poly(acrylic acid), poly(sodium \\ 4-styrenesulfonate), poly(diallyldimethylammonium chloride) and poly(arylamine) (PAAM) were studied. Surface coating of the \\ $\mathrm{CaCO}_{3}$ particles with PAAM, an aqueous dispersion, was successfully achieved by the addition of a specified concentration of \\ the polymer. The surface-coated $\mathrm{CaCO}_{3}$ particles with gold nanoparticles were obtained by addition of an aqueous solution \\ of gold nanoparticles stabilized with HYPAM-ONa to an aqueous dispersion of the $\mathrm{CaCO}_{3}$ particles and subsequent addition \\ of $\mathrm{HAuCl}_{4}$ and formaldehyde as a reducing agent.
}

Polymer Journal (2012) 44, 586-593; doi:10.1038/pj.2012.28; published online 28 March 2012

Keywords: calcium carbonate; carbonate-controlled addition method; gold nanoparticles; hyperbranched polymer; vaterite

\section{INTRODUCTION}

Because of their special properties and low cost, considerable attention has been given to synthetic organic-inorganic hybrid materials, which are inspired by biominerals. ${ }^{1-6}$ The main inorganic mineral produced in natural organisms is $\mathrm{CaCO}_{3}$; organic-inorganic hybrid materials containing $\mathrm{CaCO}_{3}$ are of great interest for industrial and technological applications. To develop methods for preparation of new $\mathrm{CaCO}_{3}$ polymer hybrid materials, a fundamental understanding of binding kinetics and mechanisms of crystallization in organic polymer- $-\mathrm{Ca}^{2+}$ complexes are required. ${ }^{7-11}$ Among various methods for preparation of $\mathrm{CaCO}_{3}$ polymer hybrid materials, carbonate-controlled addition is a way to control the mineralization of $\mathrm{CaCO}_{3}$ by simply changing the incubation time of the polymer$\mathrm{Ca}^{2+}$ complexation process in aqueous solutions before addition of $\mathrm{CO}_{3}{ }^{2-}$ ions. ${ }^{12}$ We showed that the carbonate-controlled addition method using poly(acrylic acid) (PAA) resulted in the formation of stable amorphous calcium carbonate composite particles. ${ }^{12}$ The resulting amorphous calcium carbonate composite particles were monodispersed spheres, and the average particle size increased from $0.18 \pm 0.04$ to $0.55 \pm 0.12 \mu \mathrm{m}$ with an increase in the incubation time of the PAA$\mathrm{CaCl}_{2}$ aqueous solution from $3 \mathrm{~min}$ to $24 \mathrm{~h}$. The interaction and the reaction kinetics of PAA with $\mathrm{Ca}^{2+}$ were important for controlling the particle size. We recently reported that size-controlled vaterite particles were obtained by the carbonate-controlled addition method with the G0.5 poly(amidoamine) (PAMAM) dendrimer containing carboxylate groups at the surface. ${ }^{13}$ The minimum average particle size was $0.69 \pm 0.07 \mu \mathrm{m}$ for particles synthesized with a $24 \mathrm{~h}$ complexation of the dendrimer- $\mathrm{Ca}^{2+}$ before the addition of $\mathrm{CO}_{2}{ }^{2-}$ ions.

In this study, we applied a carbonate-controlled addition method using a carboxylate-terminated hyperbranched PAMAM for preparation of $\mathrm{CaCO}_{3}$ particles (Figure 1). The properties of the resulting particles were compared with those of the $\mathrm{CaCO}_{3}$ particles using the G0.5 PAMAM dendrimer, which is a polymer particle composite that was previously reported. ${ }^{13}$ Although hyperbranched polymers have several practical advantages over the dendrimers, few studies using hyperbranched polymers for preparing $\mathrm{CaCO}_{3}$ particles have been reported. ${ }^{14-16}$ Here, we obtained size-controlled vaterite particles using carboxylate-terminated hyperbranched PAMAM by performing a carbonate-controlled addition. We also reported surface coating of the vaterite composite particles with different polymers and gold nanoparticles.

\section{EXPERIMENTAL PROCEDURE}

Materials

Unless stated otherwise, all reagents and chemicals were obtained from commercial sources and used without further purification. PAAs $\left(M_{w}: 5000\right.$ 


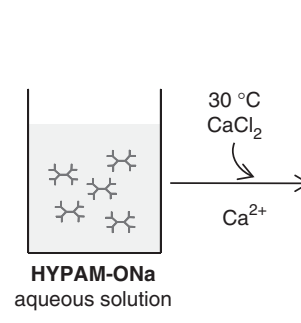

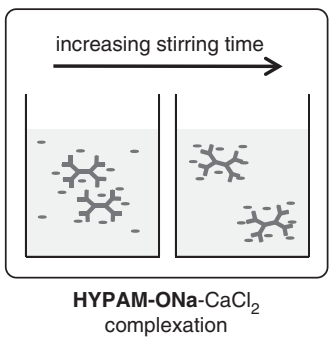

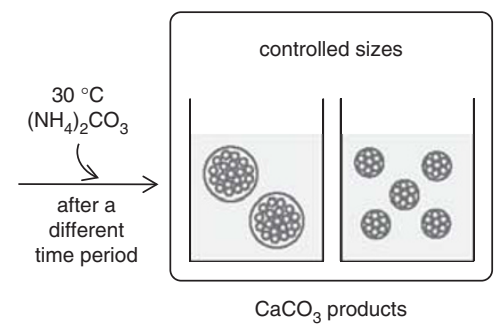

Figure 1 Schematic illustration of the carbonate-controlled addition method. A full color version of this figure is available at Polymer Journal online.

and 250000 ) were purchased from WAKO Pure Chemical Industries, Ltd. (Osaka, Japan). Poly(arylamine) (PAAM) $\left(M_{w}: 15000\right)$ was purchased from Nittobo Medical Co., Ltd. (Tokyo, Japan). Poly(sodium 4-styrenesulfonate) $\left(M_{w}: 70000\right)$ and poly(diallyldimethylammonium chloride) $\left(M_{w}: 100000 \sim\right.$ 200000 ) were purchased from Sigma-Aldrich Chemical Co. (St Louis, MO, USA). Methyl acrylate was distilled under reduced pressure and stored under nitrogen before use. Tris(2-di(methyl acrylate)-aminoethyl)amine was synthesized according to the method of Dvornic. ${ }^{17}$

\section{Measurements}

X-ray diffraction (XRD) was recorded on a Smart Lab (Rigaku, Akishima, Japan) with CuK $\alpha$ radiation $(r=1.5406 \AA)$ in $\theta / 2 \theta$ mode at room temperature. The $2 \theta$ scans were collected at $0.01^{\circ}$ intervals, and the scan speed was $2^{\circ}(2 \theta)$ min. Fourier transform infrared (FT-IR) spectra were recorded with a FT-IR 4100 (JASCO, Tokyo, Japan) using a KBr pellet method. The morphology of $\mathrm{CaCO}_{3}$ particles was observed by scanning electron microscopy (SEM) using an EV-8800 (KEYENCE, Osaka, Japan) and field emission SEM (FE-SEM) using a JSM-7600F (JEOL Ltd, Tokyo, Japan). Elemental analysis of the particles was performed by energy-dispersive X-ray spectrometry (EDX) using an X-max (OXFORD Instruments, Oxfordshire, UK). Thermogravimetric analysis (TGA) was conducted using on a TGA-2950 (TA-Instruments, New Castle, PA, USA) at a heating rate of $10^{\circ} \mathrm{C}$ per min in air. Ultraviolet-visible spectroscopy was performed using a V-670 (JASCO, Tokyo, Japan). Nuclear magnetic resonance (NMR) was performed with a PDX-300 $(300 \mathrm{MHz}$ or $400 \mathrm{MHz}$ ) (Bruker Biospin GmbH, Rheinstetten, Germany). The molecular weight was measured by gel permeation chromatography with a TOSOH 8020 (TOSOH, Tokyo, Japan) using a TSK-gel a-M column calibrated with standard poly(styrene) using dimethylformamide solution containing $10 \mathrm{mM} \mathrm{LiBr}$ as an eluent.

\section{Methylester-terminated hyperbranched PAMAM (HYPAM-OCH ${ }_{3}$ )} Amino-terminated hyperbranched PAMAM denoted as HYPAM, which is chemically analogous to the 4 th generation of the PAMAM dendrimers, was synthesized according to the method of Pérignon. ${ }^{18} \operatorname{Tris}(2$ aminoethyl)amine $(1.6 \mathrm{~g}, 11 \mathrm{mmol})$ was mixed with tris(2-di(methyl acrylate)-aminoethyl)amine $(0.70 \mathrm{~g}, 1.1 \mathrm{mmol})$. The solution was stirred under nitrogen at $75^{\circ} \mathrm{C}$ for 2 days. After the resulting dispersion was dissolved in $\mathrm{CH}_{2} \mathrm{Cl}_{2}(5 \mathrm{ml})$ and poured into THF $(200 \mathrm{ml})$ at $0{ }^{\circ} \mathrm{C}$, HYPAM was obtained as a yellow gum. The HYPAM yield was $1.5 \mathrm{~g}$. The ${ }^{1} \mathrm{H}$ and ${ }^{13} \mathrm{C}$ NMR data for HYPAM were in agreement with data in the literature. ${ }^{18}$ A methanol solution $(15 \mathrm{ml})$ of HYPAM $(1.5 \mathrm{~g})$ was mixed with methyl acrylate $(18 \mathrm{ml})$. The solution was stirred under nitrogen at $40{ }^{\circ} \mathrm{C}$ for 5 days. After the reaction mixture was poured into $200 \mathrm{ml}$ of diethylether at $0^{\circ} \mathrm{C}$, methylester-terminated hyperbranched PAMAM $\left(\mathbf{H Y P A M}-\mathbf{O C H}_{3}\right)$ was obtained as a yellow gum. The HYPAM-OCH yield was $2.0 \mathrm{~g}$.

${ }^{1} \mathrm{H} \quad \mathrm{NMR} \quad\left(\mathrm{D}_{2} \mathrm{O}, \quad 300 \mathrm{MHz}\right): \quad 2.44\left(\mathrm{br} \quad \mathrm{s}, \quad-\mathrm{CH}_{2} \mathrm{CO}-\right), \quad 2.57-2.59$ (br, $\left.\mathrm{NCH}_{2} \mathrm{CH}_{2} \mathrm{~N}\right), 2.68\left(\right.$ br s, $\left.\mathrm{CONHCH}_{2} \mathrm{CH}_{2} \mathrm{~N}\right), 2.84\left(\right.$ br s, $\mathrm{NCH}_{2} \mathrm{CH}_{2} \mathrm{CO}$ ), 3.33 (br s, $\left.-\mathrm{CH}_{2} \mathrm{NHCO}-\right), 3.71\left(\mathrm{~s},-\mathrm{OCH}_{3}\right),{ }^{1} \mathrm{H}$ NMR $\left(\mathrm{CDCl}_{3}, 300 \mathrm{MHz}\right)$ : 2.25 (br s, $\left.-\mathrm{CH}_{2} \mathrm{CO}-\right), 2.35-2.45\left(\mathrm{br}, \mathrm{NCH}_{2} \mathrm{CH}_{2} \mathrm{~N}\right), 2.53\left(\mathrm{~m},-\mathrm{CONHCH}_{2} \mathrm{CH}_{2} \mathrm{~N}\right.$ ), $2.75-2.80$ (m, $\mathrm{NCH}_{2} \mathrm{CH}_{2} \mathrm{CO}$ ), 3.25(br s, $\left.-\mathrm{CH}_{2} \mathrm{NHCO}-\right), 3.66\left(\mathrm{~s},-\mathrm{OCH}_{3}\right) ;{ }^{13} \mathrm{C}$ NMR $\left(\mathrm{CDCl}_{3}, 300 \mathrm{MHz}\right)$ : 32.5 $\left(\mathrm{CH}_{2} \mathrm{CO}\right), 33.2\left(\mathrm{CH}_{2} \mathrm{CO}\right), 37.5\left(\mathrm{CH}_{2} \mathrm{NHCO}\right)$, $49.7\left(\mathrm{NCH}_{2} \mathrm{CH}_{2} \mathrm{CO}\right), \quad 51.9\left(-\mathrm{CONHCH}_{2} \mathrm{CH}_{2} \mathrm{~N}\right), \quad 52.6\left(\mathrm{COOCH}_{3}\right), \quad 59.8$ $\left(\mathrm{NCH}_{2} \mathrm{CH}_{2} \mathrm{~N}\right), 160.1(\mathrm{COO}), 173.0(\mathrm{CONH})$.

\section{Carboxylate-terminated hyperbranched PAMAM (HYPAM-ONa)} To a methanol solution $(10 \mathrm{ml})$ of $\mathbf{H Y P A M}-\mathbf{O C H}_{3}(0.92 \mathrm{~g})$ a $1 \mathrm{M} \mathrm{NaOH}$ aqueous solution $(20 \mathrm{ml})$ was added. After the reaction mixture was refluxed for $2 \mathrm{~h}$, the solvent was removed under reduced pressure. The residues were purified by size exclusion chromatography (LH-20) using a methanol eluent to obtain sodium carboxylate-terminated hyperbranched PAMAM (HYPAM$\mathrm{ONa}$ ) as a yellow powder. The HYPAM-ONa yield was $1.2 \mathrm{~g}$.

${ }^{1} \mathrm{H}$ NMR $\left(\mathrm{D}_{2} \mathrm{O}, 300 \mathrm{MHz}\right): 2.43$ (br s, $\left.-\mathrm{CH}_{2} \mathrm{CO}-\right), 2.72\left(\right.$ br s, $\mathrm{NCH}_{2} \mathrm{CH}_{2} \mathrm{~N}$ ), 2.82(br s, $\left.-\mathrm{CH}_{2} \mathrm{NHCO}-\right),{ }^{13} \mathrm{C}$ NMR $\left(\mathrm{D}_{2} \mathrm{O}, \quad 300 \mathrm{MHz}\right): 35.4\left(\mathrm{CH}_{2} \mathrm{CO}\right)$, 37.0 $\left(\mathrm{CH}_{2} \mathrm{NHCO}\right), 39.2\left(\mathrm{CH}_{2} \mathrm{NH}_{2}\right), 51.7\left(\mathrm{NCH}_{2}\right), 52.8\left(\mathrm{NCH}_{2}\right), 53.8\left(\mathrm{NCH}_{2}\right)$, 177.5(CONH), 184.1(COO).

\section{Determining the amount of unmodified primary amine in HYPAM-ONa}

A 2,4,6-trinitrobenzenesulfonic acid (TNBS) $\operatorname{method}^{19}$ was performed to determine the amount of unmodified primary amine in HYPAM-ONa. To a $0.1 \mathrm{~m}$ sodium tetraborate aqueous solution of HYPAM-ONa, $0.03 \mathrm{M}$ TNBS aqueous solution was added. After stirring at room temperature for $1 \mathrm{~h}$, the reaction solution was measured by UV-vis analysis at $420 \mathrm{~nm}$. A standard curve for measuring the sample was obtained using tris(2-di(methyl)aminoethyl)amine.

\section{Precipitation of $\mathrm{CaCO}_{3}$}

Standard preparation of $\mathrm{CaCO}_{3}$ precipitate was carried out as follows. First, a stock aqueous solution of HYPAM-ONa (60 mg in $45 \mathrm{ml}$ of distilled water) was prepared in distilled water, and the $\mathrm{pH}$ was adjusted to 11 using a dilute aqueous solution of $\mathrm{NaOH}$. Then, $2.5 \mathrm{ml}$ of a $0.1 \mathrm{M} \mathrm{CaCl}_{2}$ aqueous solution (adjusted to $\mathrm{pH} 8.5$ with aqueous $\mathrm{NH}_{3}$ ) was added dropwise at a rate of $1 \mathrm{ml}$ per min to $45 \mathrm{ml}$ aqueous HYPAM-ONa solution under gentle stirring at $30^{\circ} \mathrm{C}$ under nitrogen. After mixing the reaction solution for durations ranging from $3 \mathrm{~min}$ to $72 \mathrm{~h}, 2.5 \mathrm{ml}$ of a $0.1 \mathrm{M}\left(\mathrm{NH}_{4}\right)_{2} \mathrm{CO}_{3}$ aqueous solution (adjusted to $\mathrm{pH}$ 10.0 with aqueous $\mathrm{NH}_{3}$ ) was added dropwise at a rate of $1 \mathrm{ml}$ per min into the reaction solution under nitrogen. This solution was stored at $30^{\circ} \mathrm{C}$ for 1 day with gentle stirring. The precipitated $\mathrm{CaCO}_{3}$ products were collected using a $0.2 \mu \mathrm{m}$-pore-sized membrane filter, washed with water several times, and then dried at room temperature under reduced pressure.

\section{Preparation of $\mathrm{CaCO}_{3}$ modified with gold nanoparticles stabilized} with HYPAM-ONa

A total of $5 \mathrm{ml}$ aqueous $\mathrm{HAuCl}_{4}$ solution $\left(2.4 \times 10^{-3} \mathrm{mmol}\right)$ was added to $5 \mathrm{ml}$ of an aqueous HYPAM-ONa solution $(6.5 \mathrm{mg}, \mathrm{pH} 11)$ under gentle stirring. As soon as the solution was mixed uniformly, $3 \mathrm{ml}$ of an aqueous $\mathrm{NaBH}_{4}$ solution $\left(6.0 \times 10^{-3} \mathrm{mmol}\right)$ was added to the mixed solution. A stock solution of gold nanoparticles stabilized with HYPAM-ONa was then obtained. The $\mathrm{CaCO}_{3}$ particles $(10 \mathrm{mg}$ ) obtained by the complexation process for $72 \mathrm{~h}$ were dispersed into distilled water $(10 \mathrm{ml})$, and $0.2 \mathrm{ml}$ of the stock solution of the gold nanoparticles stabilized with HYPAM-ONa was added into the dispersion of $\mathrm{CaCO}_{3}$ particles every $15 \mathrm{~min}$ for a total of eight times, and the dispersion was gently stirred. The dispersion was stored at room temperature for 1 day. The precipitated red-colored products were collected using a $0.2-\mu \mathrm{m}$-pore-sized membrane filter, washed with water several times, and then dried at room temperature under reduced pressure to obtain red-colored $\mathrm{CaCO}_{3}$ particles $(6.6 \mathrm{mg})$. The red-colored $\mathrm{CaCO}_{3}$ particles $(6.0 \mathrm{mg})$ were dispersed into 
methanol $(5 \mathrm{ml})$. To this dispersion, $1 \mathrm{ml}$ of an aqueous $\mathrm{HAuCl}_{4}$ solution $\left(2.4 \times 10^{-3} \mathrm{mmol}\right)$ was added with gentle stirring. Next, $1 \mathrm{ml}$ of an aqueous HCHO solution $\left(1.2 \times 10^{-3} \mathrm{mmol}\right)$ was immediately added into the dispersion. The dispersion was stored at room temperature for 1 day. The resulting dark purple-colored $\mathrm{CaCO}_{3}$ products were collected using a $0.2-\mu \mathrm{m}$-pore-sized membrane filter, washed with methanol several times, and dried at room temperature under reduced pressure to obtain purple-colored $\mathrm{CaCO}_{3}$ particles (4.4 mg).

\section{RESULTS AND DISCUSSION}

Synthesis of sodium carboxylate-terminated hyperbranched

\section{PAMAM}

The synthesis of a methyl ester-terminated hyperbranched polymer $\left(\mathbf{H Y P A M}-\mathrm{OCH}_{3}\right)$, with a structure similar to that of the PAMAM dendrimer, was based on a method described by Pérignon. ${ }^{18}$ After the polymerization of excess amounts of tris(2-aminoethyl)amine with tris(2-di(methyl acrylate)-aminoethyl)amine, a Michael reaction was carried out with methyl acrylate to obtain $\mathbf{H Y P A M}-\mathbf{O C H}_{3}$ (Scheme 1). When the molar ratio of (tris(2-aminoethyl)amine)/ (tris(2-di(methyl acrylate)-aminoethyl)amine) was 10 , the weightaverage molecular weight $\left(M_{w}\right)$ and number-average molecular weight $\left(M_{n}\right)$ of HYPAM-OCH $\mathbf{O C H}_{3}$ were 12300 and 6500, respectively, based on poly(styrene) standards. The molecular weight of HYPAM$\mathrm{OCH}_{3}$ is close to that of the G4 amino-terminated PAMAM dendrimer $\left(M_{w}=14215\right)$. The sodium carboxylate-terminated HYPAM (HYPAM-ONa) was quantitatively obtained by treatment of $\mathbf{H Y P A M}-\mathrm{OCH}_{3}$ with $\mathrm{NaOH}$. The ${ }^{1} \mathrm{H}$ and ${ }^{13} \mathrm{C}$ NMR analysis of HYPAM-ONa indicated complete deprotection. According to the TNBS method ${ }^{19}$ for HYPAM-ONa, the unreacted primary amine in HYPAM-ONa was $6.8 \times 10^{-4} \mathrm{~mol} \%$. This supports the ${ }^{1} \mathrm{H}$ and ${ }^{13} \mathrm{C}$ NMR data for HYPAM-ONa.

Effect of the incubation time of the HYPAM-ONa-CaCl 2 solution on the formation of calcium carbonate particles

A $\mathrm{CaCl}_{2}$ aqueous solution was added to an aqueous solution of HYPAM-ONa and stirred at $30^{\circ} \mathrm{C}$. Before the addition of an aqueous $\left(\mathrm{NH}_{4}\right)_{2} \mathrm{CO}_{3}$, the solution was not turbid, even after incubation for $72 \mathrm{~h}$. After the aqueous $\left(\mathrm{NH}_{4}\right)_{2} \mathrm{CO}_{3}$ solution was added to the reaction mixture at different time periods (from $3 \mathrm{~min}$ to $72 \mathrm{~h}$ ), the solution became turbid. The reaction mixtures were stored at $30^{\circ} \mathrm{C}$ for 1 day, and the products were collected using a $0.2-\mu \mathrm{m}$-pore-sized membrane filter. The crystal $\mathrm{CaCO}_{3}$ phases of the obtained products were characterized by FT-IR analysis. All the products obtained from the incubation time of $3 \mathrm{~min}, 1 \mathrm{~h}, 24 \mathrm{~h}$ and $72 \mathrm{~h}$ showed two characteristic bands at 877 and $745 \mathrm{~cm}^{-1}$ by FT-IR, indicating vaterite formation (Figure 2). The crystalline phases of the $\mathrm{CaCO}_{3}$ products were also confirmed by XRD analysis (Figure 3). SEM observations showed that all the obtained particles were spherical (Figure 4).
The average particle size decreased from $1.3 \pm 0.2$ to $0.36 \pm 0.18 \mu \mathrm{m}$ with an increase in the incubation time of the HYPAM-ONa- $\mathrm{CaCl}_{2}$ solution from $3 \mathrm{~min}$ to $72 \mathrm{~h}$ (Table 1). These characteristics were similar to the trends observed in G0.5 PAMAM dendrimers that were previously reported. ${ }^{13}$

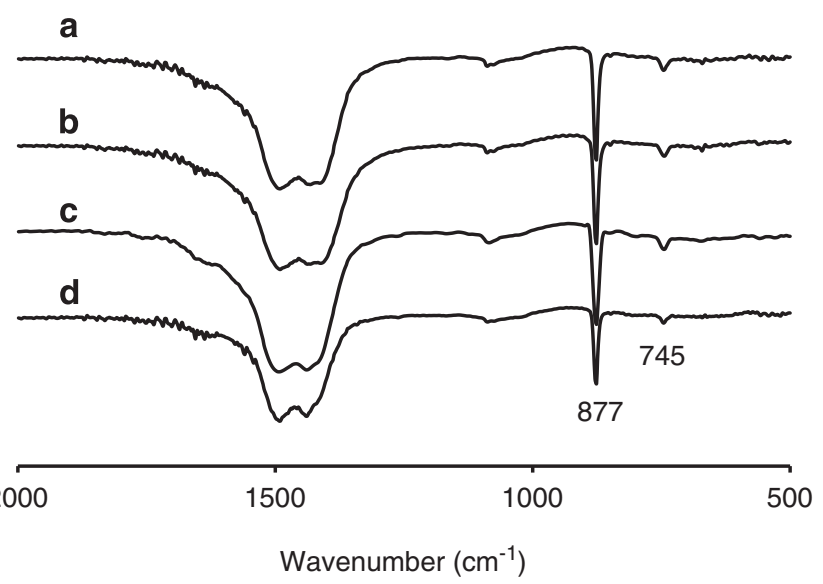

Figure $2 \mathrm{FT}-\mathrm{IR}$ spectra of the HYPAM-ONa-CaCO particles by the carbonate-controlled addition method at different incubation times of (a) $3 \mathrm{~min}$, (b) $1 \mathrm{~h}$, (c) $24 \mathrm{~h}$, and (d) $72 \mathrm{~h}$; These correspond to sample 1, 2, 3 and 4 in Table 1, respectively.

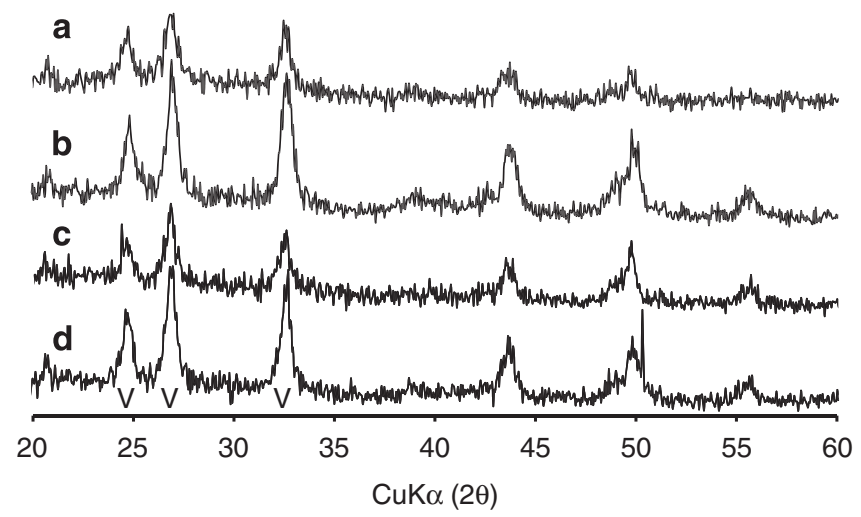

Figure 3 Comparison of XRD patterns of the HYPAM-ONa- $\mathrm{CaCO}_{3}$ particles by the carbonate-controlled addition method at different incubation times of (a) $3 \mathrm{~min}$, (b) $1 \mathrm{~h}$, (c) $24 \mathrm{~h}$, and (d) $72 \mathrm{~h}$; These correspond to sample 1 , 2,3 and 4 in Table 1 , respectively. The characteristic of XRD patterns for vaterite (d-spacing $/ 2 \theta$ peak: $3.58 \AA / 24.9^{\circ}, 3.3 \AA / 27^{\circ}, 2.73 \AA / 32.8^{\circ}$, corresponding to $h k l: 110,111,112$, respectively).

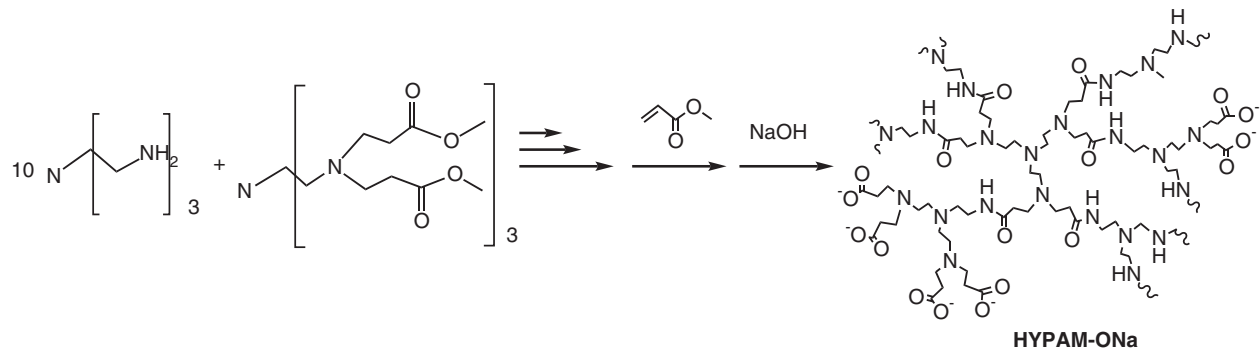

Scheme 1 Synthesis of HYPAM-ONa. 

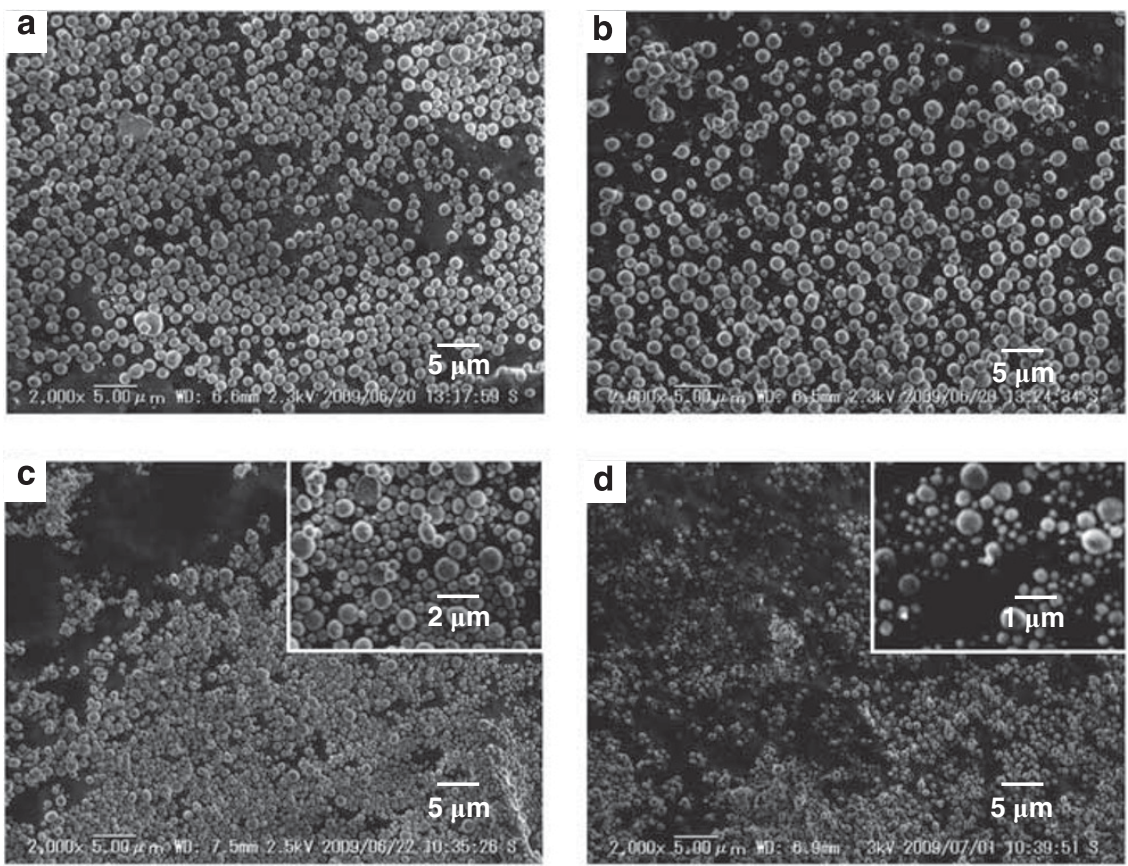

Figure $4 \mathrm{SEM}$ images of the HYPAM-ONa-CaCO 3 particles by the addition of $\left(\mathrm{NH}_{4}\right)_{2} \mathrm{CO}_{3}$ after incubating the $\mathbf{H Y P A M}-\mathrm{ONa}-\mathrm{CaCl} 2$ solution for (a) 3 min, (b) $1 \mathrm{~h}$, (c) $24 \mathrm{~h}$, and (d) $72 \mathrm{~h}$; These correspond to sample 1, 2, 3 and 4 in Table 1, respectively.

Table 1 Effect of the incubation time of the HYPAM-ONa- $\mathrm{CaCl}_{2}$ solution on mineralization of $\mathrm{CaCO}_{3}{ }^{\mathrm{a}}$

\begin{tabular}{cccccc}
\hline Run & $\begin{array}{c}\text { Particle size } \\
\text { of } \mathrm{CaCO}_{3} \\
(\mu \mathrm{m})^{\mathrm{b}}\end{array}$ & $\begin{array}{c}\text { Yield } \\
(\%)^{\mathrm{c}}\end{array}$ & $\begin{array}{c}\text { Adsorbed amount } \\
\text { of HYPAM-ONa } \\
(\text { time }\end{array}$ & $\begin{array}{c}\text { Adsorbed } \\
\text { amount of }\end{array}$ & $\begin{array}{c}\mathrm{H}_{2} \mathrm{O}(\text { (wt\%) } \\
\text { d }\end{array}$ \\
\hline 1 & $3 \mathrm{~min}$ & $1.3 \pm 0.2$ & 92 & 8.7 & 6.9 \\
3 & $1 \mathrm{~h}$ & $1.2 \pm 0.3$ & 80 & 8.0 & 5.3 \\
4 & $24 \mathrm{~h}$ & $0.61 \pm 0.28$ & 100 & 7.9 & 4.7 \\
& $72 \mathrm{~h}$ & $0.36 \pm 0.18$ & 88 & 7.9 & 4.6
\end{tabular}

aThe concentration of HYPAM-ONa was $60 \mathrm{mg}$ in $45 \mathrm{ml}$ of distilled water, and $\mathrm{CaCl}_{2}$ was $25 \mathrm{~mm}(\mathrm{pH} 8.5)$, and $\left(\mathrm{NH}_{4}\right)_{2} \mathrm{CO}_{3}$ was $25 \mathrm{~mm}(\mathrm{pH} \mathrm{10.0)}$.

bMeasured by SEM, and the number of the measured particles was 20.

${ }^{\mathrm{c}}$ Calculated based on $\mathrm{CaCO}_{3}$.

dMeasured by TGA.

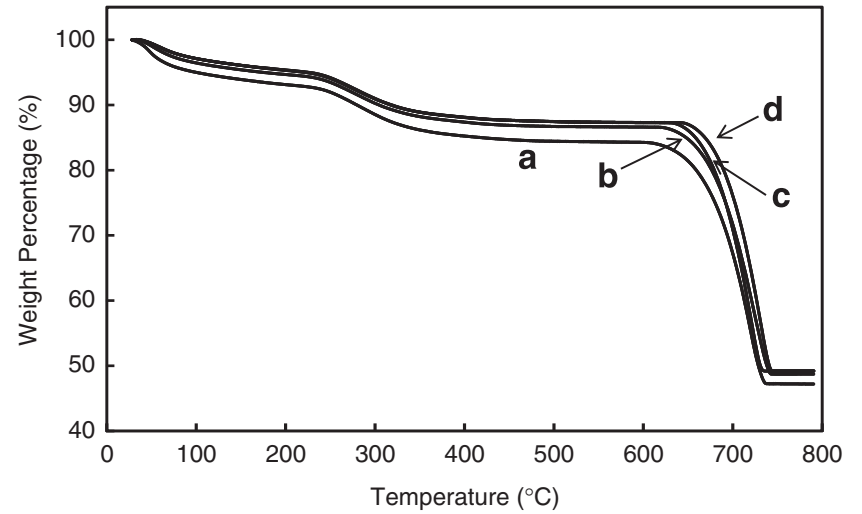

Figure 5 TGA thermographs of the HYPAM-ONa-CaCO 3 particles synthesized by a carbonate-controlled addition method at different incubation times of (a) $3 \mathrm{~min}$, (b) $1 \mathrm{~h}$, (c) $24 \mathrm{~h}$, and (d) $72 \mathrm{~h}$; These correspond to sample 1, 2, 3 and 4 in Table 1 , respectively.
The composition of the vaterite particles was estimated by TGA (Figure 5). The results are summarized in Table 1. The TGA analysis showed that the content of $\mathrm{H}_{2} \mathrm{O}$ in the particles decreased from 6.9 to $4.6 \mathrm{wt} \%$ as the incubation time of the HYPAM-ONa- $\mathrm{CaCl}_{2}$ solution increased. The contents of the organic parts in all of the products were approximately $8 \mathrm{wt} \%$.

Vaterite is the most thermodynamically unstable form among the three crystal structures of $\mathrm{CaCO}_{3}$. It is well-known that vaterite transforms into thermodynamically stable calcite within few days in an aqueous solution at room temperature. However, none of the vaterite particles transformed to stable calcite when the particles were stirred in distilled water for more than 3 days at room temperature. These results indicate that the surface of the vaterite particles was stabilized by HYPAM-ONa, which prevented phase transformation. These characteristics were similar to trends observed in G0.5 PAMAM dendrimers, as previously reported. ${ }^{13}$

Surface properties of the calcium carbonate particles

The dispersibility of the $\mathrm{CaCO}_{3}$ composite particles was estimated by turbidity measurements. The dispersibility of an aqueous solution of the HYPAM-ONa- $\mathrm{CaCO}_{3}$ particles was compared with that of the previously prepared G0.5 PAMAM dendrimer- $\mathrm{CaCO}_{3}$ particles. ${ }^{13}$ The size of the HYPAM-ONa- $\mathrm{CaCO}_{3}$ particles and the G0.5 PAMAM dendrimer- $\mathrm{CaCO}_{3}$ particles used here were $0.61 \pm 0.28 \mu \mathrm{m}$ and $0.85 \pm 0.16 \mu \mathrm{m}$, respectively. Both the HYPAM-ONa-CaCO 3 particles and the G0.5 PAMAM dendrimer- $\mathrm{CaCO}_{3}$ particles were obtained by the carbonate-controlled addition method based on a complexation time of $24 \mathrm{~h}$. Figure 6 shows that the dispersibility of the HYPAMONa-CaCO 3 particles in water was improved compared with the G0.5 PAMAM dendrimer- $\mathrm{CaCO}_{3}$ particles. The TGA analysis of the $\mathrm{CaCO}_{3}$ particles indicated that the HYPAM-ONa and G0.5 PAMAM dendrimer content of the $\mathrm{CaCO}_{3}$ particles was $8 \mathrm{wt} \%$ and $4 \mathrm{wt} \%$, respectively. The higher dispersibility of the HYPAM-ONa-CaCO particles might be due to the higher polymer content in the particles 
compared with G0.5 PAMAM dendrimer- $\mathrm{CaCO}_{3}$ particles. It should be noted that the dispersibility of the HYPAM-ONa-CaCO 3 particles in methanol were significantly improved compared with the G0.5 PAMAM dendrimer- $\mathrm{CaCO}_{3}$ particles.

To further understand the surface properties of the HYPAM-ONa$\mathrm{CaCO}_{3}$ particles, we studied interactions of the $\mathrm{CaCO}_{3}$ particles with different types of commercially available ionic polymers. The HYPAM-ONa- $\mathrm{CaCO}_{3}$ particles $(1.0 \mathrm{mg})$ obtained by the complexation time of $3 \mathrm{~min}$ were dispersed in water $(20 \mathrm{ml})$, and $2 \mathrm{ml}$ of an aqueous solution containing an ionic polymer $\left(1 \mathrm{mg} \mathrm{m}^{-1}\right)$ was added. After the dispersion was stored overnight at room temperature, the precipitates were filtered with a $0.2-\mu \mathrm{m}$-pore-sized membrane. An aqueous solution of poly(sodium 4-styrenesulfonate) ( $\left.M_{w}: 70000\right)$ $(\mathrm{pH} 7)$, an anionic polymer, was added to the dispersion of the $\mathrm{CaCO}_{3}$ particles, causing no change to the dispersion of the $\mathrm{CaCO}_{3}$ particles. Addition of an aqueous solution of PAA $\left(M_{w}: 250000\right)$, after adjusting to $\mathrm{pH} 7$, also resulted in no change of particle dispersion. These results indicate that the anionic moieties in the polymers were only slightly interacting with the protonated tertiary amine units in HYPAM-ONa. Conversely, addition of an aqueous solution of poly(diallyldimethyl ammonium chloride) (PDDA) $\left(M_{w}\right.$ : $100000 \sim 200000)(\mathrm{pH} 7)$ as a cationic polymer resulted in transformation of the polymorphic $\mathrm{CaCO}_{3}$ particles to thermodynamically stable calcite. Because the morphology of the calcite, observed by SEM, was a typical rhombohedral crystal, PDDA might strip HYPAM-ONa from the $\mathrm{CaCO}_{3}$ particles as a result of strong ionic

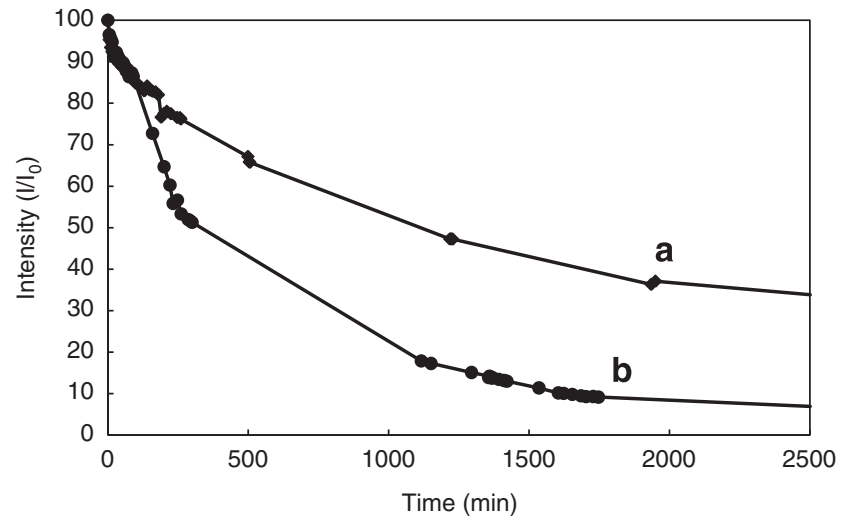

Figure 6 The turbidity of the aqueous dispersions $(4 \mathrm{ml})$ of the HYPAMONa-CaCO 3 particles $\left(1.0 \mathrm{mg}\right.$ ) (a) and the G0.5 PAMAM dendrimer- $\mathrm{CaCO}_{3}$ particles $(1.0 \mathrm{mg}$ ) (b) measurements at $500 \mathrm{~nm}$. The size of the HYPAM$\mathrm{ONa}_{-} \mathrm{CaCO}_{3}$ particles and the G0.5 PAMAM dendrimer-CaCO 3 particles were $0.61 \pm 0.28 \mu \mathrm{m}$ and $0.85 \pm 0.16 \mu \mathrm{m}$, respectively, both of which were obtained by a carbonate-controlled addition method with $24 \mathrm{~h}$ complexation. interaction between the anionic parts of HYPAM-ONa and the cationic groups in PDDA. Addition of an aqueous solution of PAAM $\left(M_{w}: 15000\right)$, with adjustment of the $\mathrm{pH}$ to 7 , caused the particles to dissolve and form a homogeneous solution. Because PAAM is regarded as a cationic polymer at $\mathrm{pH} 7$, PAAM might also strip HYPAM-ONa from the $\mathrm{CaCO}_{3}$ particles as a result of strong ionic interactions between the anionic parts of HYPAM-ONa and the cationic groups in PAAM.

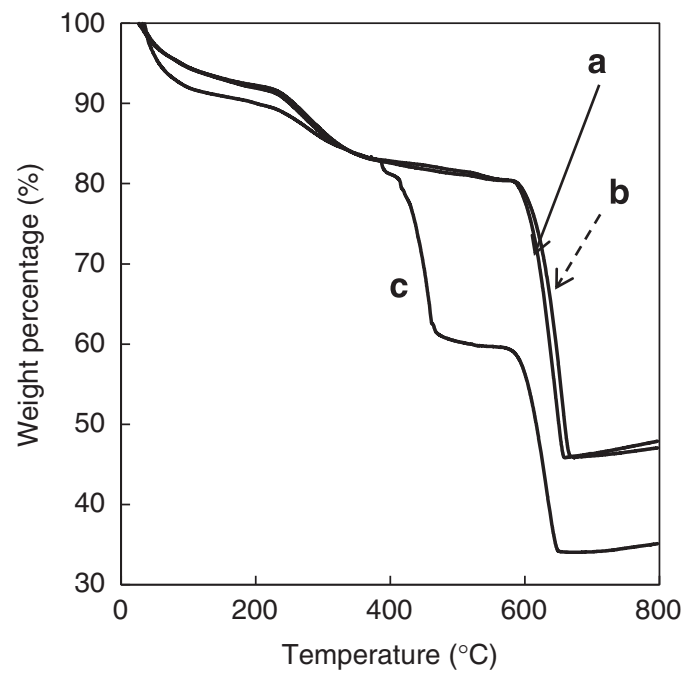

Figure $8 \mathrm{TGA}$ thermographs of the $\mathrm{CaCO}_{3}$ particles coated by PAAM using aqueous solutions containing (a) 0.1 , (b) 1 and (c) $10 \mathrm{mg} \mathrm{ml}^{-1}$ of PAAM; These correspond to samples 1,2 and 3 in Table 2, respectively.

Table 2 Analysis of TGA measurements of the obtained $\mathrm{CaCO}_{3}$ particles coating by PAAM

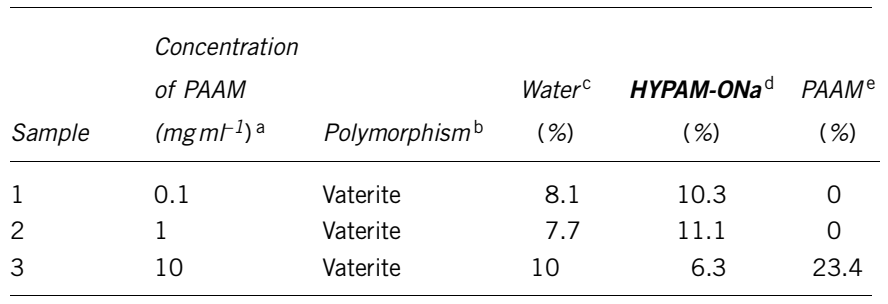

${ }^{a} 6.0 \mathrm{mg}$ of the $\mathrm{CaCO}_{3}$ particles obtained by the complexation time for 3 min was added into the $10 \mathrm{ml}$ of the PAAM aqueous solution $(\mathrm{pH} \mathrm{10)}$.

betermined by FT-IR.

CMeasured by TGA between room temperature and $200{ }^{\circ} \mathrm{C}$.

${ }^{d}$ Measured by TGA between $200^{\circ} \mathrm{C}$ and $400^{\circ} \mathrm{C}$.

e Measured by TGA between $400^{\circ} \mathrm{C}$ and $500{ }^{\circ} \mathrm{C}$.
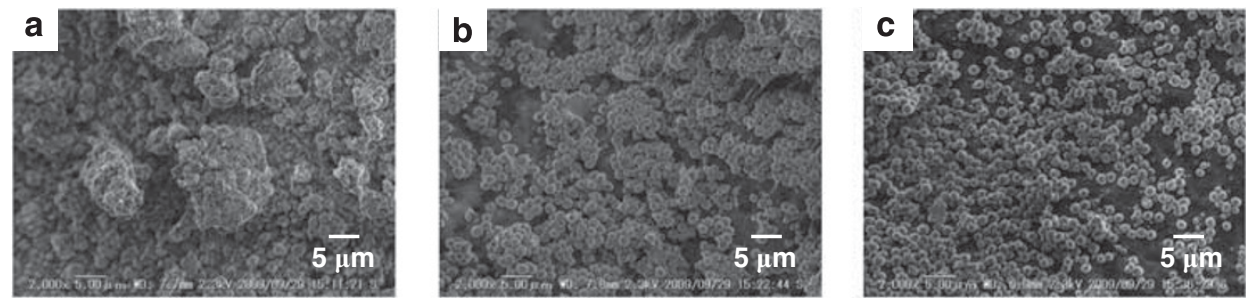

Figure $7 \mathrm{SEM}$ images of the $\mathrm{CaCO}_{3}$ particles coated by PAAM using aqueous solutions containing (a) 0.1 , (b) 1 and (c) $10 \mathrm{mg} / \mathrm{ml}^{-1}$ of PAAM; These correspond to samples 1, 2, and 3 in Table 2, respectively. 
The effects of PAA and PAAM at $\mathrm{pH} 10$ on the dispersion of the HYPAM-ONa- $\mathrm{CaCO}_{3}$ particles were significantly different from those at $\mathrm{pH}$ 7. When an aqueous solution of PAA $\left(M_{w}: 250000\right)$ (adjusted to $\mathrm{pH} 10$ with aqueous $\mathrm{NaOH}$ ) was added to the dispersion of the $\mathrm{CaCO}_{3}$ particles, the particles were immediately aggregated to form precipitates. The polymorphs of the resulting precipitates were still vaterite, as determined by FT-IR analysis. Addition of an aqueous solution of a lower molecular weight PAA $\left(M_{w}: 5000\right)$ (adjusted to $\mathrm{pH}$ 10 with aqueous $\mathrm{NaOH}$ ) to the dispersion of the $\mathrm{CaCO}_{3}$ particles also immediately caused sedimentation. After a $24 \mathrm{~h}$ incubation, the precipitates dissolved to form a homogeneous solution. These results suggest that the interaction between PAA and $\mathrm{Ca}^{2+}$ was stronger than the interaction between HYPAM-ONa and $\mathrm{Ca}^{2+}$. Because the mobility of the lower molecular weight PAA might be greater than that of the higher molecular weight PAA, dissolution of the $\mathrm{CaCO}_{3}$ particles by the former is faster than that of the later. In the case of

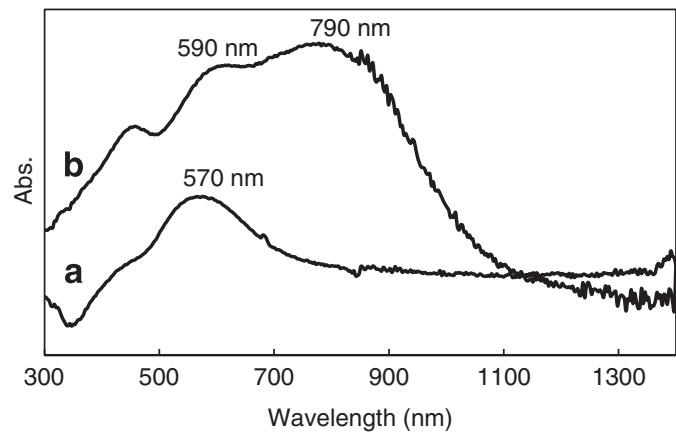

Figure 9 Solid-state UV-vis absorption spectra of (a) the red-colored precursor $\mathrm{CaCO}_{3}$ particles and (b) the final dark purple-colored $\mathrm{CaCO}_{3}$ particles after addition of $\mathrm{HAuCl}_{4}$ and $\mathrm{HCHO}$.
PAAM ( $\left.M_{w}: 15000\right)$ (adjusted to $\left.\mathrm{pH} 10\right)$ addition to the dispersion of $\mathrm{CaCO}_{3}$ particles, the particles were gradually precipitated in the dispersion within several hours. The SEM analysis of the precipitates showed aggregates of the $\mathrm{CaCO}_{3}$ particles. On the basis of FT-IR analysis, the polymorph of the particles was found to be vaterite. These results indicate that hydrogen interaction between the amide groups of HYPAM-ONa and the amino groups PAAM likely contributes to the formation of $\mathrm{CaCO}_{3}$ particle aggregates.

We studied the effect of PAAM addition (aqueous solutions of different concentrations) to the $\mathrm{CaCO}_{3}$ particles to coat the particles with PAAM. An aqueous solution $(2 \mathrm{ml})$ containing $0.1 \mathrm{mg} \mathrm{m}^{-1}$, $1 \mathrm{mg} \mathrm{ml}^{-1}$, or $10 \mathrm{mg} \mathrm{m}^{-1}$ of PAAM was added to the aqueous dispersion of $1.0 \mathrm{mg}$ of HYPAM-ONa- $\mathrm{CaCO}_{3}$ particles prepared by a complexation duration of $3 \mathrm{~min}$. After the dispersion was stored overnight, the particles were filtered with a $0.2-\mu \mathrm{m}$-pore-sized membrane. SEM analysis showed that significant aggregation of the $\mathrm{CaCO}_{3}$ particles occurred with $\operatorname{PAAM}\left(0.1 \mathrm{mg} \mathrm{ml}^{-1}\right)$ (Figure $7 \mathrm{a}$ ). However, based on SEM analysis, addition of $10 \mathrm{mg} \mathrm{m}^{-1}$ of PAAM, resulted in no particle aggregation (Figure 7c). On the basis of FT-IR analysis, the polymorphs for all of the particles were found to be vaterite. The TGA analysis of the particles obtained by the addition of $10 \mathrm{mg} \mathrm{ml}^{-1}$ of PAAM showed two clear weight losses at 350 and $450{ }^{\circ} \mathrm{C}$ (Figure 8). The former and latter species are derived from decompositions of HYPAM-ONa and PAAM, respectively. The contents of both polymers in the particles, as estimated by the TGA analysis, are summarized in Table 2 . The particles obtained by the addition of $10 \mathrm{mg} \mathrm{ml}^{-1}$ of PAAM consisted of $6.3 \mathrm{wt} \%$ of HYPAM$\mathrm{ONa}$ and $23 \mathrm{wt} \%$ of PAAM. These results suggest that surface coating of the HYPAM-ONa-CaCO 3 particles with PAAM was successfully achieved by controlling the concentration of PAAM in aqueous solutions. The particles obtained by the addition of 0.1 and $1 \mathrm{mg}$ $\mathrm{ml}^{-1}$ of PAAM consisted of $10.3 \mathrm{wt} \%$ and $11.1 \%$ of PAAM, respectively, and no detectable weight loss was observed at $450{ }^{\circ} \mathrm{C}$.
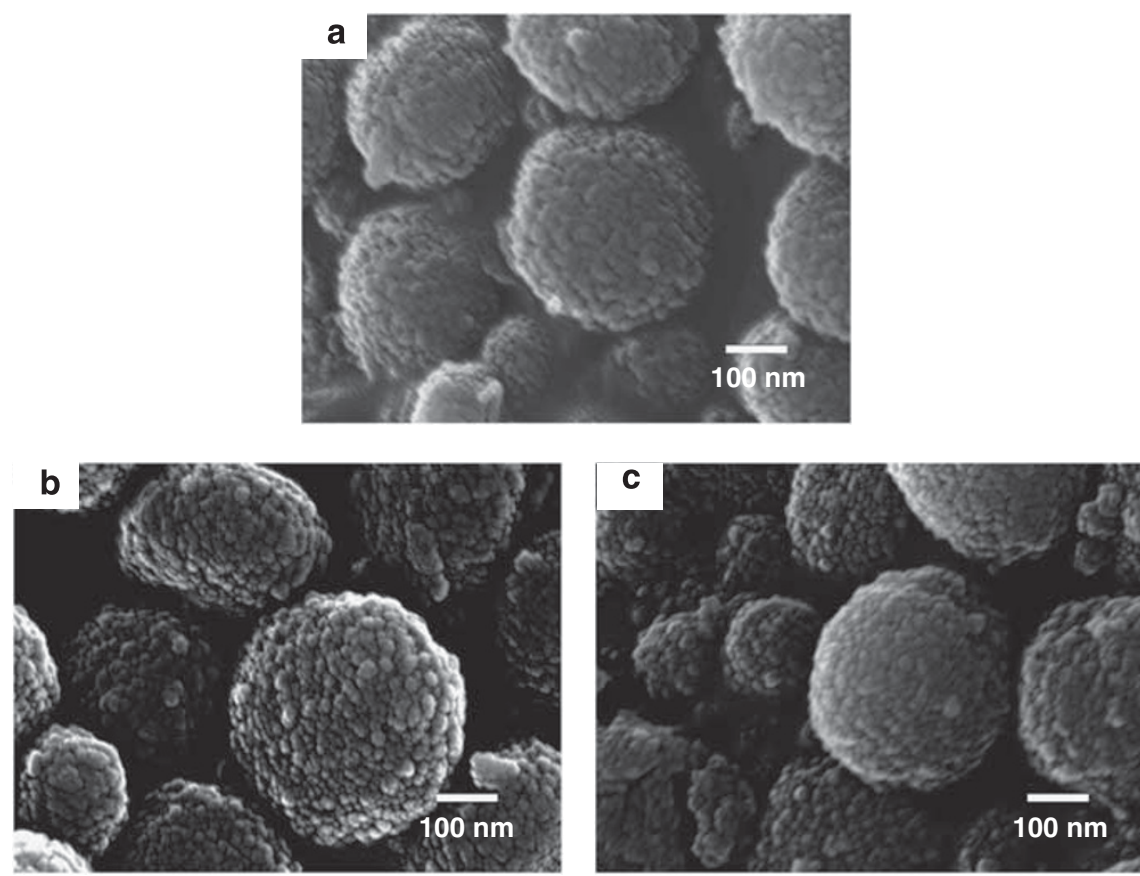

Figure $10 \mathrm{FE}-\mathrm{SEM}$ images of (a) the pristine HYPAM-ONa-CaCO 3 particles, (b) the red-colored precursor $\mathrm{CaCO}_{3}$ particles, and (c) the final dark purple-colored $\mathrm{CaCO}_{3}$ particles after addition of $\mathrm{HAuCl}_{4}$ and $\mathrm{HCHO}$. The samples were vapor-deposited with $\mathrm{Pt}$ and measured at $15 \mathrm{kV}$. 


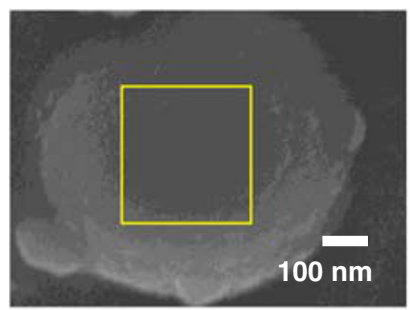

b
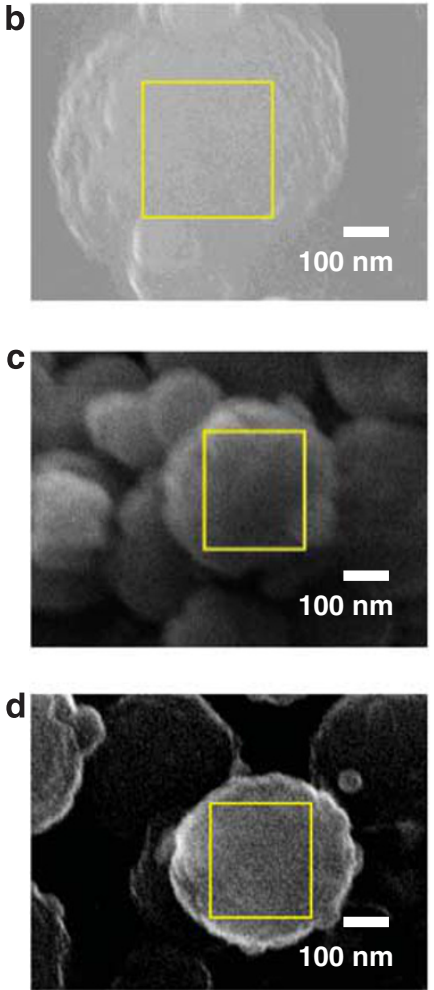

$\operatorname{EDX}(\mathrm{Ca})$
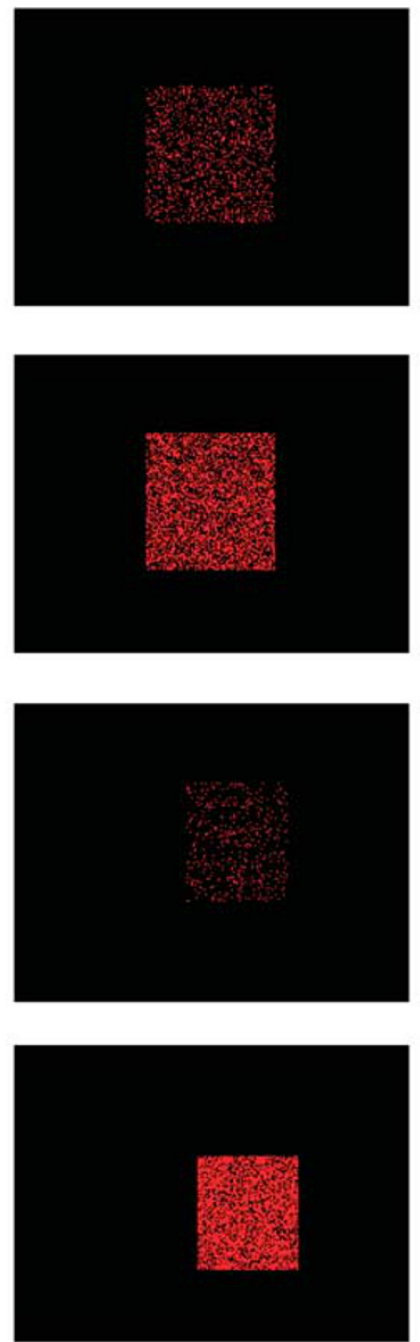

$\operatorname{EDX}(\mathrm{Au})$
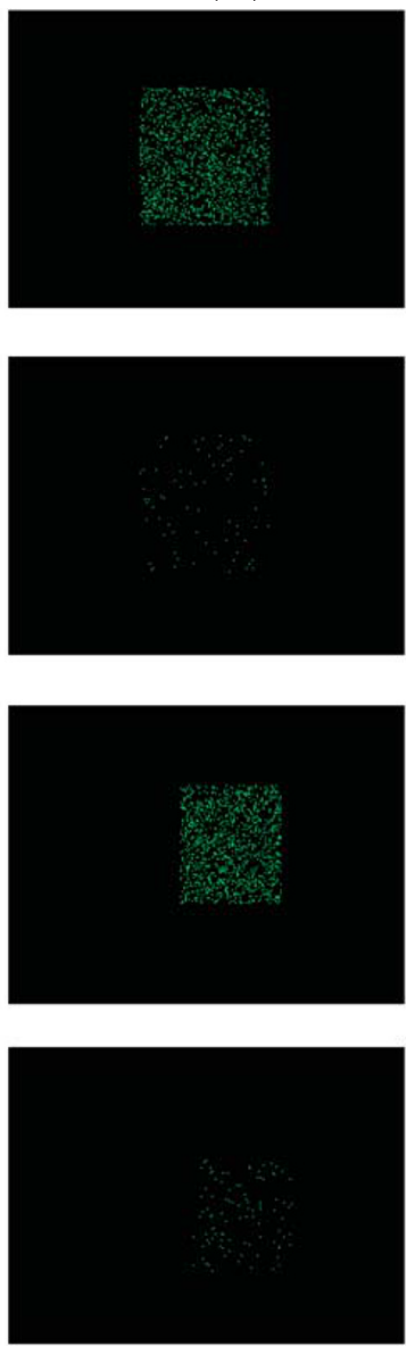

Figure $11 \mathrm{FE}-\mathrm{SEM}$ images and EDX of the red-colored precursor $\mathrm{CaCO}_{3}$ particles measured at $5 \mathrm{kV}$ (a) and $15 \mathrm{kV}$ (b), and the final dark purple-colored $\mathrm{CaCO}_{3}$ particles after addition of $\mathrm{HAuCl}_{4}$ and $\mathrm{HCHO}$ measured at $5 \mathrm{kV}(\mathbf{c})$ and $15 \mathrm{kV}$ (d). All samples were vapor-deposited with carbon.

\section{Surface modification of calcium carbonate particles by gold nanoparticles}

Gold nanoparticles stabilized with HYPAM-ONa served as a precursor solution for surface modification of the $\mathrm{CaCO}_{3}$ particles and were prepared by treating an aqueous solution containing HYPAM$\mathrm{ONa}$ and $\mathrm{HAuCl}_{4}$ (adjusted $\mathrm{pH} 11$ with aqueous $\mathrm{NaOH}$ ) with $\mathrm{NaBH}_{4}$. The molar ratios of $\left[\mathrm{HAuCl}_{4}\right] /[$ HYPAM-ONa $]$ and $\left[\mathrm{NaBH}_{4}\right] /[\mathrm{Au}]$ were 6.2 and 2.2 , respectively. ${ }^{20}$ The precursor solution was gradually added to a dispersion of $\mathrm{CaCO}_{3}$ particles obtained by the $72 \mathrm{~h}$ complexation. After the dispersion was stirred overnight at room temperature, the resulting products were isolated as red-colored precursor $\mathrm{CaCO}_{3}$ particles, of which vaterite was the primary crystalline phase, as determined by FT-IR analysis. These results indicate that no transformation of the crystalline phase occurred during this process.

To a methanol dispersion of the red-colored precursor $\mathrm{CaCO}_{3}$ particles, aqueous $\mathrm{HAuCl}_{4}$ and formaldehyde solutions were added. The color of the dispersion immediately changed from red to darkblue. After the dispersion was stored overnight at room temperature, the resulting products were isolated as dark purple-colored $\mathrm{CaCO}_{3}$ particles. The polymorph of the $\mathrm{CaCO}_{3}$ particles was still vaterite, as determined by FT-IR analysis, indicating that no transformation of the crystalline phase had occurred. The solid-state UV-vis absorption spectra of the red-colored precursor $\mathrm{CaCO}_{3}$ particles and the dark purple-colored $\mathrm{CaCO}_{3}$ particles are shown in Figure 9. The surface plasmon bands of the red-colored precursor particles and the final $\mathrm{CaCO}_{3}$ particles were observed at $570 \mathrm{~nm}-790 \mathrm{~nm}$, respectively. A redshifted surface plasmon band is a consequence of increased overlap of the dipole resonances between neighboring gold nanoparticles on the surface of the dark purple-colored $\mathrm{CaCO}_{3}$ particles compared with that of the red-colored precursor $\mathrm{CaCO}_{3}$ particles. According to the TGA analysis of the final dark purple-colored $\mathrm{CaCO}_{3}$ particles, the gold quantity was determined as $9 \mathrm{wt} \%$.

The FE-SEM image of the resulting red-colored precursor particles shows that nanoparticles that are $8.8 \pm 0.8 \mathrm{~nm}$ in diameter cover the surface of the $\mathrm{CaCO}_{3}$ composite particles (Figure 10b). Conversely, the pristine HYPAM-ONa-CaCO 3 particles have a rather smooth surface composed of $35 \pm 4 \mathrm{~nm}$ particles, based on the FE-SEM image (Figure 10a). Vaterite particles are usually obtained as a spherical shaped poly crystal, which is constructed of $25-35 \mathrm{~nm}$ nano-crystallites. $^{21,22}$ The $8.8 \pm 0.8 \mathrm{~nm}$ nanoparticles observed on the surface of the red-colored particles might be assigned to the gold nanoparticle 
precursors. The composition of the red-colored precursor particles was further probed by an EDX analysis. From the distribution of $\mathrm{Au}$ and $\mathrm{Ca}$ in the red-colored precursor particles measured by the EDX analysis at an electron-accelerating voltage of $5 \mathrm{kV}, \mathrm{Au}$ and $\mathrm{Ca}$ were uniformly distributed on the particle (Figure 11a). However, in the same area of the EDX image at an electron-accelerating voltage of $15 \mathrm{kV}$, only $\mathrm{Ca}$ signals were detected (Figure $11 \mathrm{~b}$ ). These results indicate that Au was mainly distributed on the surface of the redcolored precursor particles. The FE-SEM images showed that the dark purple-colored particles have a rather smooth surface (Figure 10c). The EDX analysis also indicates that Au was distributed on the surface of the final dark purple-colored $\mathrm{CaCO}_{3}$ particles (Figures $11 \mathrm{c}$ and $\mathrm{d}$ ). On the basis of the results from the TGA analysis, the calculated thickness of the gold nanoparticle layer on the surface of the $\mathrm{CaCO}_{3}$ particles is less than several nanometers.

\section{CONCLUSIONS}

In this study, the size-controlled $\mathrm{CaCO}_{3}$ particles with HYPAM-ONa were synthesized using a carbonate-controlled addition method. The average sizes of the $\mathrm{CaCO}_{3}$ particles decreased from $1.3 \pm 0.2 \mu \mathrm{m}$ to $0.36 \pm 0.18 \mu \mathrm{m}$ with an increase in the incubation time of the HYPAM-ONa- $\mathrm{CaCl}_{2}$ solution from $3 \mathrm{~min}$ to $72 \mathrm{~h}$. All of the $\mathrm{CaCO}_{3}$ particles obtained were composed of vaterite. The dispersibility of the HYPAM-ONa- $\mathrm{CaCO}_{3}$ particles in distilled water and methanol was improved compared with those of the G0.5 PAMAM dendrimer$\mathrm{CaCO}_{3}$ particles, as previously prepared. ${ }^{13}$ We also found that surface coating of the HYPAM-ONa-CaCO 3 particles with PAAM was successfully achieved by controlling the concentration of PAAM in aqueous solutions. Hydrogen interactions between the amide groups of HYPAM-ONa and the amino groups PAAM likely contribute to the formation of $\mathrm{CaCO}_{3}$ particle aggregates. Gold nanoparticle-coated $\mathrm{CaCO}_{3}$ composite particles were also obtained adding an aqueous solution of gold nanoparticles stabilized with HYPAM-ONa to the HYPAM-ONa- $\mathrm{CaCO}_{3}$ particles and subsequently adding $\mathrm{HAuCl}_{4}$ and formaldehyde. The surface plasmon band of the gold nanoparticlecoated $\mathrm{CaCO}_{3}$ particles appeared at $790 \mathrm{~nm}$. The present composite particles can serve as components of a new class of nanomaterials that are capable of controlling radiation in the near infrared spectral regions.
1 Kato, T., Sugawara, A. \& Hosoda, N. Calcium carbonate organic hybrid materials. Adv. Mater. 14, 869-877 (2002).

2 Aizenberg, J. Crystallization in patterns: a bio-inspired approach. Adv. Mater. 16, 1295-1302 (2004).

3 Jaffrés, P. -A. \& Morris, R. E. Synthesis of highly functionalized dendrimers based on polyhedral silsesquioxane cores. J. Chem. Soc. Dalton Trans. 2767-2770 (1998)

4 Sanchez, C. Arribart, H. \& Guille, M. M. G. Biomimetism and bioinspiration as tools for the design of innovative materials and systems. Nature Mater. 4, 277-288 (2005).

5 Evans, J. S. 'Tuning in' to mollusk shell nacre- and prismatic-associated protein terminal sequences. implications for biomineralization and the construction of high performance inorganic-organic composites. Chem. Rev. 108, 4455-4462 (2008).

6 Munch, E., Launey, M. E., Alsem, D. H., Saiz, E., Tomsia, A. P. \& Ritchie, R. O. Tough, bio-inspired hybrid materials. Science 322, 1516-1520 (2008).

7 Naka, K. Biomineralization I: Crystallization and Self-organization Process (SpringerVerlag, Berline, Heidelberg, 2007).

8 Naka, K. Biomineralization II: Mineralization Using Synthetic Polymers and Templates (Springer-Verlag, Berline, Heidelberg (2007).

9 Naka, K. \& Chujo, Y. Control of crystal nucleation and growth of calcium carbonate by synthetic substrates. Chem. Mater. 13, 3245-3259 (2001).

10 Sommerdijk, N. A. J. M. \& de With, G. Biomimetic $\mathrm{CaCO}_{3}$ mineralization using designer molecules and interfaces. Chem. Rev. 108, 4499-4550 (2008).

11 Meldrum, F. C. \& Cölfen, H. Controlling mineral morphologies and structures in biological and synthetic systems. Chem. Rev. 108, 4332-4432 (2008).

12 Huang, S.-C., Naka, K. \& Chujo, Y. A Carbonate controlled-addition method for amorphous calcium carbonate spheres stabilized by poly(acrylic acid)s. Langmuir 23, 12086-12095 (2007).

13 Tanaka, Y. \& Naka, K. A Carbonate controlled-addition method for size-controlled calcium carbonate spheres by carboxylic acid terminated poly(amidoamine) dendrimers. Polym. J. 42, 676-683 (2010).

14 Meng, O., Chen, D., Yue, L., Fang, J., Zhao, H. \& Wang, L. Hyperbranched polyesters with carboxylic or sulfonic acid functional groups for crystallization modification of calcium carbonate. Macromol. Chem. Phys. 208, 474-484 (2007).

15 Dong, W., Cheng, H., Yao, Y., Zhou, Y., Tong, G., Yan, D., Lai, Y. \& Li, W. Bioinspired synthesis of calcium carbonate hollow spheres with a nacre-type laminated microstructure. Langmuir 27, 366-370 (2011).

16 Wang, G., Li, L., Lan, J., Chen, L. \& You, J. Biomimetic crystallization of calcium carbonate spherules controlled by hyperbranched polyglycerols. J. Mater. Chem. 18, 2789-2797 (2008).

17 Dvornic, P. R., Hu, J., Meier, D. J., Nowak, R. M. \& Parham, P. L. U.S patent 0161113 Al (2002).

18 Perignon, N., Marty, J. D., Mingotaud, A. F., Dumont, M., Rico-Lattes, I. \& Mingotaud, C. Hyperbranched polymers analogous to PAMAM dendrimers for the formation and stabilization of gold nanoparticles. Macromolecules 40, 3034-3041 (2007).

19 Snyder, S. L. \& Sobocinski, P. Z. An improved 2,4,6-trinitrobenzenesulfonic acid method for the determination of amines. Anal. Biochem. 64, 284-288 (1975).

20 Perignon, N., Mingotaud, A. F., Marty, J. D., Rico-Lattes, I. \& Mingotaud, C. Formation and Stabilization in water of metal nanoparticles by a hyperbranched polymer chemically analogous to PAMAM dendrimers. Chem. Mater. 16, 4856-4858 (2007).

21 Brečević, L., Nöthig-Laslo, V., Kralj, D. \& Popović, S. Effect of divalent cations on the formation and structure of calcium carbonate polymorphs. J. Chem. Soc. Faraday Trans. 92, 1017-1022 (1996).

22 Beck, R. \& Andreassen, J. P. Spherulitic growth of calcium carbonate. Cryst. Growth Des. 10, 2943-2947 (2010). 